https://doi.org/10.21670/ref.1904025

Artículos

\title{
Identidad y migración rural: Un enfoque fenomenológico
}

\author{
Identity and rural migration: A phenomenological \\ approach
}

\author{
Felipe de Jesús Rodríguez ${ }^{\mathrm{a}}$ (ID) https://orcid.org/0000-0002-1877-0076 \\ Sergio Moctezuma a* (D) https://orcid.org/0000-0002-0545-4218 \\ Humberto Thomé Ortiz ${ }^{\mathrm{a}}$ (D) https://orcid.org/0000-0002-6714-3490
}

Recibido el 29 de septiembre de 2018.

Aceptado el 20 de marzo de 2019.

Publicado el 2 de abril de 2019.

${ }^{*}$ Autor para correspondencia: Sergio Moctezuma, correo electrónico smoctezumap@uaemex.mx
Esta obra está protegida bajo una Licencia Creative Commons Atribución-NoComercial 4.0 Internacional. a Universidad Autónoma del Estado de México, Instituto de Ciencias Agropecuarias y Rurales, México, correos electrónicos: fejus-rodiz@icloud.com; smoctezumap@uaemex.mx; humbertothome@ hotmail.com

\section{Resumen}

El objetivo del presente artículo es analizar las experiencias de migrantes retornados en Tejupilco, Estado de México. Se utiliza como eje teórico y metodológico la epojéfenomenológica, aplicada a diez individuos que migraron a Estados Unidos y que por diferentes razones regresaron a México (agosto-noviembre de 2017). De esta forma, se parte de la premisa de que es necesario profundizar en la experiencia migratoria más allá del conocimiento pragmático establecido y fundamentar las experiencias de los individuos de manera fáctica. Los resultados muestran que existe una necesidad en las ciencias sociales por apreciar de manera fenomenológica el tema migratorio. Se demuestra la existencia de una identidad migratoria de naturaleza dinámica que no depende de definiciones macrosociales, sino de la actividad que realiza el sujeto como capacidad de ser actor social. Asimismo, denota la manera en que los migrantes asimilan el significado de la experiencia, fuente del sentido trascendental que representa actualmente su estilo de vida.

Palabras clave: epojé fenomenológica, experiencia migratoria, actor social, conciencia, agencia.

\section{Abstract}

The objective of the paper is to analyze the experiences of returned migrants in Tejupilco, State of Mexico. We use the phenomenological epoche as a theoretical and methodological axis, and we apply it to ten individuals who migrated to the United States that for different reasons returned to Mexico

CÓMO CITAR: Rodríguez, F. J., Moctezuma, S. y Thomé, H. (2019). Identidad y migración rural: Un enfoque fenomenológico [Identity and rural migration: A phenomenological approach]. Estudios Fronterizos, 20, e025. doi:https://doi.org/10.21670/ref.1904025 
(August-November 2007). In this way, the paper starts from the premise that it is necessary to deepen the migratory experience, beyond the established pragmatic knowledge, and to base the experiences of the individuals in a factual way. The results show the need for the social sciences to appreciate the migration issue in a phenomenological way. The findings demonstrated the existence a migratory identity of dynamic nature that does not depend on macrosocial factors but depends on the activity performed by the subject as a social actor. Likewise, the results allow us to conclude that the way in which migrants assimilate the meaning of experience is a source of transcendental meaning that currently represents their lifestyle.

Keywords: phenomenological epoche, migratory experience, social actor, conscience, human agency.

\section{Introducción ${ }^{1}$}

La causa de la migración México-Estados Unidos está motivada por la disparidad en los ingresos, donde la percepción sobre el bienestar económico en el país de acogida es superior al que el migrante percibe en su país de origen (Arizpe, 2015). Asimismo, el constante ir y venir de migrantes mexicanos ha desarrollado un sistema transnacional y de fácil acceso a través de redes sociales (Anguiano y Cardoso, 2012; Ariza y Portes, 2007; González, 2012). Esto es evidente en la mayoría de las comunidades en México donde la causa principal, sigue siendo la limitación laboral en la localidad de origen. Más aún, a pesar del esfuerzo laboral, algunos de los migrantes de retorno no encuentran un panorama asequible para explotar cualidades y habilidades adquiridas en la trayectoria migratoria (Gandini, Lozano-Asencio y Gaspar, 2015; Nicolás, 2016; Rivera, 2016). En el caso del Estado de México, según la Encuesta sobre Migración de Mexiquenses a Estados Unidos (EMMEU) de 1970 a 2009, pasó del vigésimo al cuarto lugar en la escala de entidades federativas con mayor índice de emigración en el país y el tercer lugar respecto a la recepción de remesas a nivel nacional (González, Montoya y López, 2012). Una de las localidades con mayor flujo migratorio en este estado es Tejupilco; que se ubica al suroeste y está integrada por los municipios de Amatepec, Luvianos, Tejupilco de Hidalgo y Tlatlaya (Salas, 2017; Salas y Alcántara, 2015). Según cifras de la Secretaría de Desarrollo Social (Sedesol, 2015), la región cuenta con más de 420 localidades, de las cuales, solo la cabecera municipal (Tejupilco de Hidalgo) y Bejucos son consideradas urbanas, las restantes son rurales y con un índice alto y muy alto de marginación.

El municipio de Tejupilco está conformado por una sociedad que absorbe las actividades laborales del campo a través de fuertes matices de migración internacional demarcados en el progreso económico de sus migrantes retornados (Salas y Alcántara, 2015). Esto puede observarse en las comunidades aledañas entre las que se encuentran: Rincón de Jaimes, Rincón de Aguirre, Rincón de López, Zacatepec, entre otras, que han sido circundadas por la mancha demográfica de nuevos poblados. Tales comunidades, en su mayoría son integradas por familias de migrantes a Estados Unidos, quienes

\footnotetext{
${ }^{1}$ Este artículo forma parte del proyecto Estrategias de sustento entre los jóvenes del medio rural en el sur del Estado de México, con clave 4091/2016SF de la Secretaría de Investigación y Estudios Avanzados de la Universidad Autónoma del Estado de México.
} 
cuentan con un estatus económico mejorado y buscan en su retorno un lugar más digno para la vivienda y condiciones de vida más aceptables en comparación con la realidad rural de su localidad de origen.

Bajo este panorama surge la premisa de que la adaptación social en el extranjero trastoca eventualmente la identidad del migrante, y se considera que dicha adaptación es desarrollada a través de múltiples vivencias sociales experimentadas en la trayectoria migratoria. Este planteamiento se inserta en las concepciones epistemológicas de la perspectiva de las ciencias sociales, fundamentadas en la fenomenología de Husserl y, específicamente, desde el enfoque de la epojé $e^{2}$ fenomenológica. El modo en que la fenomenología opera analíticamente en las experiencias describe la manera en que esta perspectiva puede instaurarse en el marco sociológico de los estudios sobre migración. El objetivo de esta investigación es proponer una aproximación teórica para emprender un análisis del fenómeno migratorio centrado en el quehacer particular de la experiencia de sus actores sociales (Long, 2007).

\section{La naturaleza teórica de la identidad en las ciencias sociales}

A partir de la década de los años cincuenta la identidad se convirtió en un concepto central tanto en las ciencias sociales como en las humanidades, donde las preocupaciones sobre problemas arraigados a la sociedad de masas se transformaron en varios enfoques establecidos en hipótesis sobre la naturaleza de la sociedad y que, actualmente constituyen base de los estudios contemporáneos (Bagga-Gupta, Hansen y Feilberg, 2017; Coté, 2006; Giménez, 1996; Schwartz, 2005). A finales del siglo xx la academia enunciaba el auge y dominio del tema de la identidad como nuevo objeto de estudio para la sociología y la antropología; fraguado en la preocupación del desarrollo de las particularidades nacionales y su tendencia a la globalización, la transnacionalización y la homologación cultural (Giménez, 1996). Esto fue observado como tendencia a una crisis social denominada crisis general de las identidades, cuya afectación recae principalmente en los países en desarrollo frente el desafío de la modernización (Dubar, 2002; Giménez, 1996). Esta crisis puede observarse actualmente en la dinámica migratoria internacional, donde el influjo capitalista expone y seduce con el beneficio del consumo moderno, pero también limita los medios económicos para adquirir tales bienes (Ariza y Portes, 2007, p. 654), provocando que individuos de sociedades en desarrollo, principalmente colectivistas, emigren a sociedades desarrolladas, marcadamente individualistas (Schwartz, 2005).

Desde este punto de vista, la identidad puede ser observada bajo la influencia de la globalización en los patrones migratorios actuales que toman los Estados nación como entidades estáticas; como categorías para definir significativamente sobre personas, ciudadanos, migrantes, quienes se desplazan a través de ellos, o dentro

\footnotetext{
${ }^{2}$ Poner fuera de acción la tesis general inherente a la esencia de la actitud natural; ponemos entre paréntesis todo lo que ella abarca ónticamente: así pues, este mundo natural entero, que está constantemente para nosotros ahí, ahí delante, y que seguirá estándolo incesantemente como realidad de que tenemos conciencia, aunque nos dé por ponerlo entre paréntesis. Si así lo hago [...], no por ello niego este mundo, como si fuera un sofista, ni dudo de su existencia, como si fuera un escéptico; pero practico la epojé fenomenológica, que me cierra por completo todo juicio sobre la existencia espacio-temporal (Husserl, 2013, p. 144).
} 
de ellos (Bagga-Gupta et al., 2017). Esto significa que el intercambio fronterizo es un ejercicio transnacional medido por políticas mercantiles globales, donde el funcionamiento de las fronteras y la migración a través de ellas también afecta la transferencia de valor interpersonal e interregional (Kearney, 2006). Sin embargo, llama la antención que el tema de la identidad no ha sido del todo considerado por los estudios migratorios (Schwartz, 2005), que en su mayoría limitan sus esfuerzos en describir el influjo y evolución de la globalización en la dinámica migratoria desde una perspectiva demográfica (Zarur, 2016). Actualmente, la literatura coincide en que las limitaciones para desarrollar investigaciones sobre el tema de la identidad obedecen a la estrechez teórica de las perspectivas del paradigma esencialista del Estado Nación (Coté, 2006; Bagga-Gupta et al., 2017; Giménez, 1996, 1997, 2000; Schwartz, 2005; Schwartz, Montgomery y Briones, 2006; Wetherell, 2010; Wetherell y Mohanty, 2010). Pese a lo anterior y en lo que va de este siglo, se han realizado trabajos delineando una perspectiva dinámica de la identidad, permeando posibles vías analíticas más allá de los patrones estáticos globales. Tal es el caso de Bucholtz y Hall (2005, p. 585) que ejemplifican el estatus actual de la identidad:

La identidad es el producto más que la fuente de prácticas lingüísticas y semióticas y, por lo tanto, un fenómeno cultural en lugar de uno principalmente psicológico; abarca categorías demográficas de nivel macro, posturas temporales e interactivamente específicas y roles de los participantes, y posiciones culturales locales, etnográficamente emergentes; puede indexarse a través de etiquetas, estilos o estructuras y sistemas lingüísticos; se construye relacionalmente a través de varios aspectos de la relación entre uno mismo y el otro, incluyendo similitud/diferencia, autenticidad/artificio y autoridad/ deslegitimación $[\ldots]$.

En este sentido, el tema de la identidad ha sido bastante debatido y poco sistematizado en función de una aplicación teórica estable. Pero también se visibiliza la necesidad de percibirla como una problemática abierta y dinámica, un sitio que reúne una amplia gama de inquietudes, tropos, patrones de pensamiento, debates de ciertos binarios y tipos particulares de coloquios (Wetherell, 2010), frente a la perspectiva esencialista y tradicionalista de los Estados que resultan un elemento de análisis débil cuando se trata de caracterizar la identidad humana (Bagga-Gupta et al., 2017).

Si bien, estas vías analíticas consideradas "revolucionarias", tienen su génesis teórica en la perspectiva fenomenológica de Husserl, instaurada por Max Weber (2014) al establecer la visión social en el individuo; actualmente, han resurgido estructuradas teóricamente en un marco de "construcción social" (Benwell y Stokoe, 2006; Long, 2007; Searle, 1997). La vertiente social de la fenomenología de Husserl y Weber se desarrolló como sistema teórico con Alfred Schütz (2004) estableciendo los lineamientos de la disciplina sociológica al proponer la relación entre subjetividad y acción. Más tarde Luckmann (discípulo de Schutz), junto con Berger redefinirán la sociología del conocimiento (Berger y Luckmann, 2003) aplicando la fenomenología del mundo de la vida cotidiana (Dreher, 2012). Esta línea fenomenológica aporta bases teóricas para la comprensión de la construcción social que proyecta Norman Long (2007) en su teoría social donde se exterioriza la identidad con un carácter de producto fluido y maleable, que se produce a medida que las personas se posicionan y adquieren posicionamiento en la interacción social a través de una variedad de contextos, incluidos los entornos discursivos (Bagga-Gupta et al., 2017). 
La pregunta que guía este trabajo es ¿de qué manera la naturaleza maleable de la identidad puede ser transformada a través de la experiencia migratoria? Actualmente el panorama del análisis migratorio en México ha dejado ver algunas consideraciones respecto a una identidad dinámica, al tratar temas como: 1) redes sociales y vínculos altruistas organizados por migrantes en los países receptores en apoyo a sus localidades de origen (Anguiano y Cardoso, 2012); 2) transnacionalismo y su vínculo con la transformación de las identidades de los migrantes (Ariza y Portes, 2007; Jardón y Corona, 2012; Nicolás, 2016); 3) inclusión de las mujeres al flujo migratorio (Salas y Baca, 2016); 4) inclusión indígena (Fox y Rivera-Salgado, 2004) y; 5) el campo de las emociones (Ariza, 2016; Sánchez, 2016). Estas vertientes muestran una investigación no solo en perspectiva demográfica y económica; poco a poco visibilizan que "la migración no se entiende (del todo) mediante una suma de abstracciones y generalidades que, con fines demostrativos y explicativos, están asentadas en pretendidos rasgos comunes del desplazamiento de seres humanos a través de fronteras y territorios" (Zarur, 2016, p. 381).

En este punto de inflexión que conjuga la naturaleza maleable de la identidad y el acercamiento cualitativo del tema migratorio, se estructura la propuesta de análisis para esta investigación, a partir del enfoque de la epojé fenomenológica que, proyectada en la teoría social de Long, permita observar la dinámica y organización de factores y relaciones internos y externos sistematizados por la acción humana y la conciencia. Esta aproximación teórica se erige con base en una identidad de carácter abierto y naturaleza dinámica, frente a la concepción del Estado nación que soslaya la capacidad de agencia y el contexto circunstancial de la experiencia migratoria. Según Long:

[...] necesitamos documentar las maneras en que las personas dirigen o enredan sus caminos en sucesivos escenarios difíciles, convirtiendo lo malo en circunstancias menos malas" [...] Esto nos llevará a esclarecer los eslabones entre los pequeños mundos de los actores locales y los fenómenos globales (Long, 2007, p. 45).

Esta actitud refleja la naturaleza de una identidad que de acuerdo con Dubet y Zapata (1989), no está dada ni es unidimensional, más bien, resulta progresivamente de la administración y de la organización experiencial del actor que reúne diversos niveles de identidad, produciendo una imagen social subjetiva de sí misma. A continuación se intenta responder a la interrogante: ¿cómo develar este resultado de la identidad en la experiencia migratoria?

\section{Epojé y experiencias: Un enfoque analítico para observar la identidad en la migración de retorno}

La fenomenología es considerada eje metodológico en el análisis de la conciencia que, como objeto de estudio, representa la unidad sistemática en la que las experiencias se vinculan y cobran sentido y significado (Husserl, 2011). El punto de partida es desprenderse del pensamiento natural que, según Husserl, desconoce "las dificultades que afectan al conocimiento en la vida y en la ciencia" (2011, p. 59) e instaurarse en actitud de observación desinteresada, cerrando "por completo todo juicio sobre 
la existencia espacio-temporal" (2013, p. 144). Dicha actitud, para Husserl (2011, p. 61 ), consiste en "no aceptar ningún conocimiento como conocimiento" lo cual, no significa la negación absoluta del mismo al ponerlo en cuestión, sino solo a aquellos rendimientos que se han atribuido al conocimiento.

La manera en que la fenomenología parte de la conciencia como objeto de estudio, es a través de la epojé, al poner entre paréntesis los prejuicios en torno al objeto de estudio que aborda. La finalidad es mostrar al objeto (las experiencias) tal como aparece a la conciencia (vivencias), neutralizando los prejuicios en torno a este y así, describir de manera pura el significado del mismo (Husserl, 2013). De esta manera " $[\ldots]$ la vivencia mientras se la vive y se reflexiona simplemente sobre ella, es indudable; la aprehensión directa e intuitiva y la posesión de la (vivencia) son ya un conocer; (luego entonces), las (experiencias) son los primeros datos absolutos" (Husserl, 2011, p. 61).

Esta actitud fenomenológica se adopta como enfoque para establecer la aproximación teórica que aquí se persigue ya que, se considera necesario profundizar el tema migratorio tomando como base la experiencia migratoria en sí misma e ir más allá del conocimiento pragmático establecido. ${ }^{3}$ Es por ello que, para dirigir el objetivo de la investigación es necesaria la epojéy, develar de qué manera la identidad de los actores sociales, inmersa en la trayectoria migratoria, es dinámica. Esto requiere lo que autores como Dubet y Zapata (1989) y Giménez (1996) denominan "retorno al sujeto". Para dar cuenta de ello, se ha tomado aquí una doble función: mostrar la reducción que realiza la epojé instalándose en las experiencias y, aplicarlo al campo de estudio que esta aproximación teórica persigue.

El contexto en que se instaura este enfoque lo delimita el fenómeno de la migración mexicana a los Estados Unidos, del cual es necesario: 1) dirigirse al sujeto: migrante mexicano retornado; 2) delimitar geográficamente el contexto donde se realiza el análisis: Tejupilco, Estado de México y 3) delinear el perfil del migrante: personas con experiencia migratoria a Estados Unidos, que hayan retornado a su lugar de origen o decidido radicar en Tejupilco. ${ }^{4}$ Estas reducciones muestran un sujeto con características específicas que lo identifican a un colectivo. La participación de este sujeto solo es visibilizada como "agente" o vínculo, entre el campo social en que se desarrolla como actor y el campo de conciencia en que se sistematizan las experiencias del mismo (Dubet y Zapata, 1989; Giménez, 1996; Husserl, 2008). Las esferas contextuales en torno al sujeto infieren ampliamente en la constitución identitaria a través de la interacción en y con tales contextos, creando el campo social (Long, 2007) o bien, mundo de la vida cotidiana (Berger y Luckmann, 2003; Husserl, 2011, 2013). La extensión de este campo social depende en tanto y cuanto a la movilidad e interacción del sujeto con su contexto, compuesto de una variedad de elementos que lo configuran, delinean y definen (Long, 2007). En el caso que nos ocupa, la extensión del campo social se visibiliza en la constitución dinámica del fenómeno

\footnotetext{
${ }^{3}$ Limitamos especificaciones y distinciones filosóficas de la epojé fenomenológica y epojé trascendental, así como las distintas reducciones eidéticas y estructuraciones noéticas y noemáticas (Husserl, 2008; 2013) que un análisis fenomenológico estricto exige. Esto no debe menospreciar lo desarrollado con anterioridad, más bien, delimita el marco epistemológico que direcciona a la investigación aquí desarrollada.

${ }^{4}$ Es importante aclarar que no existe interés en diferenciar las personas migrantes en categorías de género, edad o condición social; ya que como se explicará adelante, nuestro interés está centrado en la observación de las experiencias y no su contextualización por categorías sociales o existenciales.
} 
migratorio: antes, durante y después; lo cual implica diferentes escenarios y categorías metodológicas de carácter dinámico.

Se considera entonces que la interacción del sujeto migrante con el campo social fundamenta la identidad; pues como señala Giménez (1997, p. 12): "[la identidad] es la autopercepción de un sujeto en relación con los otros; a lo que corresponde, a su vez, el reconocimiento y la 'aprobación' de los otros sujetos”. Sin embargo, lo que interesa a los objetivos de esta investigación, no es la manera en que infieren estas circunstancias o estructuras en el delineamiento del sujeto (en ninguna escala o grado), sino, lo "vivido" por el sujeto en dicha interacción ante y en tales circunstancias, como experiencia de lo acontecido. De esta manera y de acuerdo con Dubet y Zapata (1989), se puede observar que la identidad es un ejercicio sobre sí a partir de categorías y relaciones dadas y no puede llevarse a cabo por definición, sino solo bajo el principio de unicidad y de la unidad; capacidad que únicamente se desarrolla a través del sujeto agente (Heidegger, 1971; 2013) y la actividad sistémica de la conciencia (Husserl, 2013; Sánchez Ortíz de Urbina, 2015).

Según Castles (2014, p. 249), la migración "es un proceso social, en el que los participantes sufren procesos de cambio y actúan [...] para modificar las condiciones y prácticas con las que se encuentran". La extensión del concepto: "proceso social" que señala el autor, incluye variedad de elementos circunstanciales, activos tangibles e intangibles que contextualizan la escena de la migración; de esta se infiere el modo en que "los participantes sufren y actúan" en dicho proceso. La pregunta es ¿cómo visibilizar y describir o analizar dichos elementos y activos que potencializan la modificación de condiciones y prácticas? La puesta entre paréntesis de la epojé a las circunstancias contextuales del sujeto (migrante), coloca el análisis en un estado asequible para observar el modo de ser de la persona en la vida cotidiana (Berger y Luckmann, 2003), en estado de factum, como hecho; pero no a la manera de las ciencias empíricas, sino como algo "hecho suyo", propio de la persona; es decir: "lo vivido" (Heidegger, 1990; Husserl, 2011; Long, 2007; Schutz y Luckmann, 2003) en tales circunstancias. Esto es conceptuado en el sentido más estricto de la palabra “aprehensión”, es decir pertenencia (Heidegger, 1990).

De manera que se puede observar al sujeto de estudio desde diferentes perspectivas: 1) el modo en que está haciendo (viviendo) las cosas: observar la acción y 2) el modo en que ha hecho (vivido) las cosas: observar el hecho. En el primer postulado el investigador puede realizar juicios: lo hace bien o mal, es correcto o incorrecto, la mejor manera de hacerlo, entre otros. En el segundo, estos juicios son suspendidos; no pueden clasificar, ordenar o referenciar; no interfieren porque no existe una acción, sino un hecho, una vivencia. Esto permite observar que los juicios son delimitados por, y dependen de, la acción y el sujeto en cuestión (migrante). El investigador no tiene acceso directo al factum (lo vivido) si no es a través de la experiencia del sujeto (Heidegger, 1971). La tarea del investigador se "reduce" a la descripción de la "aprehensión" del sujeto, es decir, del hecho que constituye lo vivido: la experiencia (Berger y Luckmann, 2003; Husserl, 2011). De esta manera, la clasificación, ordenamiento y referencias causales (al contexto) dependen únicamente de lo dado, es decir, de lo que se observe en la descripción de la experiencia. Esto es de suma importancia debido a que: las circunstancias contextuales (campo social) están implícitas como correlatos de conciencia, lo que significa que son los contenidos esenciales de las experiencias (Husserl, 1997, 2011 y 2013). 
El enfoque que proveé la epojé depura el modo en que el migrante delata su integración a una cultura diferente a través del relato de sus vivencias (experiencias); en él discurre el significado sin prejuicios sociales ni estructurales, y narra el proceso en que se modifican las condiciones y prácticas del mundo de la vida y la identidad, sea personal, social o cultural. Con lo anterior se describe una metodología maleable, con categorías previamente establecidas y categorías desarrolladas inductivamente en el contexto del análisis. De modo que se propone mostrar la manera en que la aproximación teórica expuesta permite ser funcional, teniendo como objetivo visibilizar la manera en que el sujeto orienta sus experiencias en la decisión y adaptación en un contexto ajeno.

\section{Metodología}

Los criterios de selección de la unidad de estudio fueron depurados a partir de la observación participante realizada en un periodo de dos años en que el investigador radicó en dicha comunidad. Entre los hallazgos destacan: a) la comunidad cuenta con un alto índice de migrantes de retorno con flujo a Estados Unidos; actividad considerada como cotidiana para la mayoría de los pobladores y $b$ ) las colonias aledañas a la cabecera municipal están constituidas por pobladores que en su mayoría no pertenecían originalmente; sin embargo y, gracias a los ingresos económicos adquiridos por la migración, les han permitido establecer una vivienda y condiciones de vida más aceptables a la realidad rural de su localidad de origen.

El trabajo de campo se realizó entre los meses de agosto a noviembre del 2017. Se inició aplicando un cuestionario al alumnado de las dos preparatorias más significativas para el municipio ( $\mathrm{n}=250$ ) (escuela Preparatoria Regional de Tejupilco y Escuela Preparatoria Anexa a la Normal de Tejupilco), con la finalidad de acumular familiares o conocidos de los alumnos con experiencia migratoria a Estados Unidos. La selección de informantes clave se realizó de modo secuencial con un muestreo selectivo no probabilístico de bola de nieve (discriminatorio) (Patton, 2002), considerando los criterios de: experiencia migratoria con tiempo mínimo de dos años y, retorno al lugar de origen o decidido radicar en el campo de estudio especificado.

Se obtuvieron 10 migrantes de retorno, 3 mujeres y 7 hombres con edades entre 31 a 53 años; 6 casos de 31 a 35, uno de 43 y 3 más de 52 a 53 años; todos son nacidos y radican actualmente en Tejupilco, aunque en diferentes localidades. ${ }^{5}$ La emigración a EE. UU. fue en dos casos en 1985, tres casos de 1995 a 1999, cuatro casos más entre 2003 y 2004 y uno en 2011. En cuanto al retorno, los más antiguos fueron en 1994 y 2000, seguidos de uno en 2007; los restantes figuran entre 2013 y 2015. La temporalidad de experiencia migratoria registró un caso de 3 años, dos de 9 años, cuatro entre 10 y 13 años, dos de 15 años y uno de 20 años; dando un promedio de 11.7 años de experiencia migratoria en el grupo.

\footnotetext{
${ }^{5}$ Dos de los informantes: Lourdes (2017) y Sergio (2017), por razones a la problemática expuesta en el contenido de la experiencia relatada, se decidió omitir la información extraída por las entrevistas. Sin embargo, consideramos pertinente sea reconocida su colaboración y participación en la investigación que sustenta este artículo.
} 
Es importante considerar que la variabilidad de las experiencias no depende del tiempo de estancia migratoria como de los acontecimientos sociales ocurridos en este y la asimilación de los hechos del migrante. De aquí que el objetivo de la investigación sea visibilizar la manera en que el sujeto orienta sus experiencias para decidir y adaptarse en un contexto ajeno. En los casos analizados la motivación de migrar radicó en la precariedad económica; empero, la realización del acto mostró que: en algunos casos el cruce de frontera fue por el desierto, otros cruzaron de manera indocumentada en auto, otros sacaron visa de turista y renovaban su estatus enviando a México solo la documentación. El estatus para todos fue irregular, tomando en cuenta que dos casos migraban continuamente con visa de turista, alargaban su estancia temporal y se desarrollaban laboralmente.

La cotidianeidad de la migración en la región mostró que 8 de los 10 migrantes mantuvieron continuidad en el ir y venir; algunos dos o tres veces, otros cinco veces y otros hasta "catorce veces o más", como en los casos de Guadalupe y Ángeles que se mencionarán más adelante. Los motivos son variables y demarcados por acontecimientos y circunstancias del contexto, así como la asimilación y decisión del migrante. Para algunos, la facilidad de la visa amplió las posibilidades del vaivén, para otros como Juan Carlos, deportado más de 4 veces, la re-inmigración representó un campo social diferente al de los demás; en el caso de José, por las circunstancias en que fue deportado, no tuvo posibilidades económicas de volver a intentarlo; o bien, el caso de Miguel, que solo realizó un viaje de 20 años, decidió no retornar pero, tras la deportación, los motivos de esta y el balance de la dificultad actual para migrar nuevamente, decidió establecerse en el lugar de origen con la seguridad obtenida por la experiencia de adquirir un estatus económico "tal vez no mejor pero posiblemente igual que en Estados Unidos" (Miguel, 2017).

En términos generales, los relatos develan en sus líneas la génesis de una historia migratoria con base en la misma realidad rural. Sin embargo, lo interesante es observar el contraste de la vivencia subjetiva entre diferentes modos de vida y, la diferencia demarcada por la asimilación contextual, la influencia familiar y cultural, el género, entre otros; las decisiones y actitudes ante las arenas de una vida completamente diferente a la de origen; las agencias realizadas frente a las vicisitudes y, sobre todo, la manera en que los migrantes asimilan el significado de la experiencia como base del sentido trascendental que actualmente representa su estilo de vida.

El tamaño de la muestra fue determinado por la observación y análisis en la diversidad de ideas obtenidas en la extracción de los datos, por lo que, una vez que estos se mostraron repetitivos se declaró punto de saturación (Strauss y Corbin, 2002). La extracción de la información fue delineada con base en la Teoría Fundamentada de Glaser y Strauss (1967), para lo cual: $a$ ) se realizaron 10 entrevistas semiestructuradas organizadas temáticamente de acuerdo con la eventualidad de la migración (antes, durante y retorno) y los objetivos planteados en la investigación; b) se realizó transcripción y edición, lectura y relectura del material adquirido en las entrevistas para buscar y entrever estructuras y significados; $c$ ) se generaron códigos de manera inductiva detectando patrones significativos en la información recabada: en el antes se consideran las causas contextuales, motivaciones, influencias, fantasías y objetivos; en el durante se tomaron en cuenta el cruce de frontera, la adaptación y el contraste de las estructuras sociales (de origen versus de acogida); y en el después se considera la readaptación identitaria tomando en cuenta las ventajas y desventajas, el aprendizaje, estilo de vida diferente, hábitos y actitudes, la reinserción laboral y 
social, reconocimiento de superación personal y comunitario y, valoración de la experiencia en el retorno. Dichos códigos se consideran subcategorías de análisis que, d) fueron contrastadas bajo codificación axial (Strauss y Corbin, 2002) en relación con las categorías previamente establecidas de la estructura teórica de Long (2007) con los conceptos de Arena, Agencia, Dominio y Livelihood. Estos a su vez, e) fueron organizados con base en la eventualidad de la migración, donde cada etapa toma el papel de contexto circunstancial en la interacción del migrante y el campo social; considerando así, f) el campo social (Long, 2007) como macrocategoría constituida de las etapas migratorias, como se muestra en la Tabla 1.

Tabla 1: Esquema de macrocategorías, categorías y subcategorías de análisis

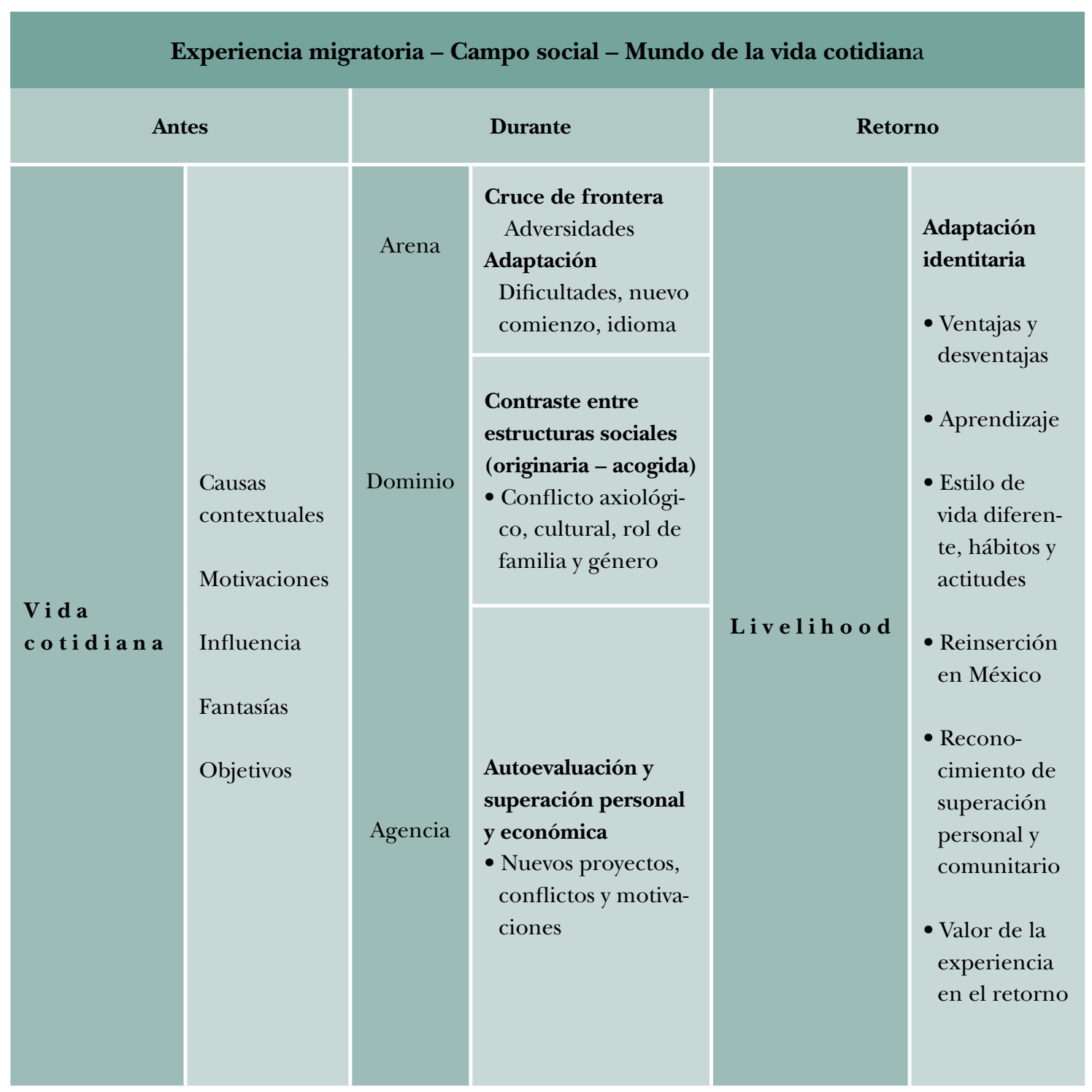

Fuente: Elaboración propia con base en Glaser y Strauss (1967), Heath y Cowley (2004) y Long (2007). 
Asimismo, los datos obtenidos fueron tratados de manera ideográfica con atención a la singularidad de acontecimientos cambiantes que configuraron las circunstancias descritas en los relatos de los migrantes, consierando así, que el retorno migratorio adquirió un significado holístico de la experiencia migratoria.

\section{Resultados}

Las etapas del fenómeno migratorio (antes, durante y después) son reducidas por la óptica de la epojéprincipalmente en la etapa del retorno. De este modo, son visibilizadas a partir del análisis de las experiencias no como ciclo, sino como contenidos de conciencia, que sistematizados adquieren el grado de significatividad de la interacción que realizó el migrante en la lucha de sus objetivos. Esto puede observarse como resultado de la conjunción entre la propuesta centrada en el actor de Long (2007) y la óptica de la epojé fenomenológica realizada en la particularidad migratoria de Tejupilco.

El contexto muestra el punto de partida para observar la restructuración de la identidad y cómo esta se sistematiza a través de la experiencia migratoria. Los resultados obtenidos revelan una sociedad rural con fuerte tendencia a la migración internacional demarcada en la actividad económica de sus migrantes retornados:

En México teníamos el terreno y los animales, pero no los peones [...] no teníamos medios para solventar ese aspecto, tú hacías todo: —subir al cerro, bajar las vacas, ordeñarlas y hacer el queso. Yo ya no quería hacerlo y tampoco que mi mamá siguiera haciendo [...] es por eso que te vas a Estados Unidos y te ganas tus dólares mejor (Guadalupe, 2017).

[...] Por eso es que vamos allá (EUA) bastante [...] encuentras gente de los alrededores, (ellos) tienen menos acceso al dinero, por eso dicen: —no, mejor vámonos al norte. Si cruzas, ya que vienes vives bien, tienes comodidades, compras tu casita y vas ahorrando [...] Son las mentalidades que uno trae para acá; pero luego, nomás son puro sueño, ideas. Otros vienen con buenas ideas de negocio pero ven que no hay posibilidades, se decepcionan y se van otra vez al norte (Abelardo, 2017).

Los actores muestran condiciones deplorables de desarrollo económico local, desapego de actividades del campo, migración rural al extranjero y economía familiar con sustento de remesas. Características observadas por la literatura, tanto a nivel nacional como estatal (González y López, 2012; Jardón y Corona, 2012; Román, 2012).

En la etapa del antes, el campo social de Long es visible en la configuración de las causas que motivaron la migración: precariedad económica del país de origen y demanda de mano de obra del país receptor. Ariel (2017) comenta: "El dinero no alcanzaba, no había suficiente en la familia [...] un amigo me dijo que estaba muy bonito (EUA), había dinero, trabajo [...]”. Por su parte Juan Carlos (2017), argumenta: "[...] por falta de recursos económicos [...] carecíamos de alimentos en la familia [...] decidí irme para ayudar a mis hermanos [...] tenía la edad de 15 años. 
Por su parte, Ángeles (2017) expone que sus motivos: "Principalmente fueron económicos, vengo de una familia de 6 hijos, soy la tercera. Originadas y criadas en rancho $[\ldots]$ mi hermana y yo decidimos irnos, sacamos visa de turista $[\ldots]$ si nos la daban nos quedaríamos a trabajar".

Se observa también, que la influencia recibida por el actor en el contraste entre los modos de vida del país de origen y el país receptor, generan ciertas fantasías que, de acuerdo con Berger y Luckmann (2003), van configurando expectativas (ilusorias) de un posible modo de ser de la vida. Así lo relata Guadalupe (2017):

(Imaginaba) algo bonito, fácil; —llegaré bien, a trabajar y todo tranquilo[...] los que ya habían ido y regresaban, así te lo pintaban: buena ropa, buenos carros, muy bien arreglados. —Allá es fácil—, decían, —llegas y todo limpio-. En los departamentos tienes lavadora, microondas, alfombra. Y tú en el rancho, con lodo y vacas..., — pues... ¡me voy! — [...] da tentación.

Dichas fantasías son proyectadas a manera de motivaciones e intenciones dirigidas hacia un objetivo (Schwartz et al., 2006). De este modo la migración, vista desde el enfoque de la epojé, comienza a estructurse en un campo irregular en el dinamismo ejercido por los actores; el cual, habrá que organizar asociativamente a través de enfrentamientos eventuales, posiblemente constantes, arduos y duraderos (Long, 2007). Probablemente el cruce representa para los migrantes un campo de batalla donde las interpretaciones de valor juegan el papel más importante. Estos espacios son para Long (2007) sitios y situaciones sociales a los que llamará: Arena. Juan Carlos (2017) explica:

Cruzamos el río en Piedras Negras y enseguida nos agarró migración [...] yo era menor de edad, me separaron y me reportaron al consulado mexicano [...] me entregaron al DIF de Piedras Negras [...] reunieron dinero [...] me subieron en el autobús, un sándwich de jamón y con eso me vine. (En el segundo intento) cruzamos por Sonora, pero del otro lado nos agarró migración $[\ldots]$ nos persiguieron por una barranca, corriendo cruzamos las cunetas del agua, pero nos llegó el helicóptero y nos deportaron.

Por su parte José (2017), menciona: "[...] ya no aguantaba [...] vi una luz a lo lejos y ahí me senté [...] —yo hasta aquí llego- [...] no llevábamos comida ni nada [...] gracias a mi amigo que conocí en Agua Prieta, llegué”. La dinámica de eventos y circunstancias desfavorables por las que atraviesa el migrante, van limando asperezas que de principio son consideradas adversas. Sin embargo, la asimilación de estas a través de la experiencia (Berger y Luckmann, 2003), permiten estructurar cierta seguridad donde el migrante cimenta nuevos pasos, técnicas y estrategias de adaptación (Long, 2007) en su proceso. Juan Carlos (2017), con más de 10 años de experiencia, comenta que "aprendí que para progresar tienes que respetar tu trabajo; llegar temprano y esforzarte más de lo normal; todo el tiempo estar al pendiente [...]; no sólo ver el hoy sino, enfocarte a futuro y verlo a largo plazo".

En la etapa del durante es importante considerar que el adentrarse a una estructura social diferente, hábitos y costumbres no practicadas en el terruño, representan para el actor, un cúmulo de experiencias que necesita discernir y adoptar para direccionar actos y objetivos (Nicolás, 2016; Schwartz, 2005). Guadalupe (2017) dice que "Fue difícil, muchos tienen la idea de que: —yo ya le sufrí, ahora tú- [...] En ocasiones el sueño americano se convierte en pesadilla; lo viví en la propia familia [...]”. Para 
José (2017), "Es como otro mundo; comida nueva, otro idioma. Tienes que empezar como niño a aprender; me hablaban y no entendía nada”. Ángeles (2017) por su parte, " $[\ldots]$ no encontraba trabajo, dos o tres meses encerrados en un cuarto porque tampoco podíamos salir [...] mi hermano tenía jornadas de 12 horas y teníamos que esperarlo en casa; ya que salía nos llevaba algo de comer". A esta práctica Long (2007, p. 48) la denomina agencia, la cual: "atribuye al actor individual la capacidad de procesar la experiencia social y diseñar maneras de lidiar con la vida, aún bajo las formas más extremas de coerción”. La agencia permite visibilizar la manera en que una experiencia, suceso o interacción, puede sobreponerse mediante su significado a nuevos contenidos experienciales y establecerse como directriz intencional de las decisiones del actor (Berger y Luckmann, 2003; Sánchez Ortíz de Urbina, 2015). Humberto (2017) menciona que:

La primera vez no llevaba nada en la mente, sólo sabía que había dinero, que estaba bonito; no llevaba ni una meta y así regresé, sin nada [...] La segunda vez sí había algo que me motivaba. Tenía de novia a la que (ahora) es mi esposa; quería casarme; y dije: - yo me voy a ir y voy a juntar dinero para poder casarme.

Lo anterior devela que la agencia juega el papel de conciencia intencional de la fenomenología husserliana, ya que atribuye al actor la capacidad de reflexionar lo experimentado y que, el resultado de esta reflexión sea la potencialización intencional de operaciones para la realización de nuevos objetivos (Husserl, 2013; Long, 2007; Sánchez Ortíz de Urbina, 2015). En este sentido, la agencia, al igual que la conciencia, siempre estará dirigida a algún objeto, "ya sea que el objeto $[\ldots]$ se experimente como parte del mundo físico exterior, o se aprehenda como elemento de una realidad subjetiva interior" (Berger y Luckmann, 2003, p. 36); permitiendo así, que el campo social en esta etapa, pueda ser estructurado como un espacio dialéctico asociativo de significados (Long, 2007). Ángeles (2017) afirma:

Esa experiencia cambió mucho a mi persona, no sería la misma que soy ahora si no me hubiera ido a sufrirle. Es una suma de ir superándote, de no quedarte con lo que eres sino luchar por ser mejor persona; no en el sentido económico nada más, sino en el aspecto personal. Por ejemplo, a mi me ayudó a ser desenvuelta, antes era muy tímida; el aprender el idioma me ayudó mucho $[\ldots]$.

Desde una perspectiva global, las transformaciones del campo social que experimenta el migrante son visibilizadas en el paso de una estructura social colectivista a una individualista (Schwartz, 2005). El choque de estas estructuras, para la mayoría de migrantes no solo representa las arenas del día a día; allende a estas, la disputa de adaptación queda representada por normas de valores intangibles y significados trascendentales que se contraponen a la estructura social originaria. Este espacio de contienda, Long (2007, p. 124) lo denominará dominio.

[...] el hecho de ser mujer [...] Mi papá era machista [...] me decía "que no, tú eres mujer ¿qué vas a hacer allá? Te vas a casar y te van a mantener, para qué estudias" [...] mi mamá decía: "si se casan y las mantienen, pero si no, ¿¿de qué van a vivir? $\mathrm{O}$ ¿is le sale un tipo borracho? Tienen que tener un oficio o algo" (Ángeles, 2017). 
La diferencia entre arena y dominio radica en que el segundo ejerce cierta influencia sobre el actor social; en la medida en que el migrante está comprometido con normas y valores del campo social de origen. Este concepto no solo permite visibilizar sendas en las que migrantes han creado significatividad colectiva como resultado demográfico, sino que permite detectar formas en que este grupo social estructura identidades colectivas con significado propio. De acuerdo con Long (2007, p. 124), los dominios: "No deben conceptuarse [...] a priori como algo dado culturalmente, sino como producidos $[\ldots]$ mediante las experiencias $[\ldots]$ y forcejeos [...] entre actores de índoles o condiciones varias". En este sentido, el concepto dominio expresa reciprocidad con el concepto "cuido" de Giménez (1993; 2000), ya que la adaptación del migrante está determinada culturalmente por la nación de origen, tanto axiológica como socialmente. Esto significa que la disputa de dominios tiene origen en el encuentro de valores y costumbres culturales: una cultura originaria y una receptora. Aquí interesa analizar el proceso en que se estructura la adaptación a valores, costumbres y normas ajenas a la constitución social del migrante y; observar de qué manera adquiere admisión a través de lo vivido como aceptación a un compromiso social nuevo. Obsérvense los casos de Tejupilco:

El trato como inmigrante [...] Son racistas; te dan trabajo, pero te castigan, no te pagan, no tienes derechos, o tienes y no los conoces [...] Son injustos, trabajas para comer y progresar, pero no puedes decir nada, tú buscas el trabajo y si no te gusta, pues vete (Juan Carlos, 2017).

Aprender a independizarme [...] En México eres la hija de papi. Sí, trabajabas en el campo, con vacas, hacías queso y demás, pero dependías de tus papás. No tenías libertad como tal [...] allá (EUA) tienes que aprender a moverte, valerte por ti misma, organizarte. A hacer todo tú. Yo como hermana mayor, como mujer, "es responsabilidad ver por tu hermana menor". Es adaptarte, independizarte, saber cómo lo ibas a hacer y todo (Guadalupe, 2017).

La aprehensión e interacción que realiza el migrante sobre el campo social, crea una red de significados propia y, genera - a nivel empírico- estrategias necesarias para adaptarse y sobrellevar vicisitudes adversas en la experiencia migratoria. Estrategias que Long (2007) denomina como Livelihood. Abelardo (2017) menciona que después de varios años de experiencia trabajando en restaurantes:

[...] en esa vez me moví a la Florida, mismo país, mismas comodidades, mismo trabajo; pero ya era mesero, más tranquilo y más dinero [...] Cuando van a la playa, van contentos, llevan dinero, van a gastar; menos estresados que cuando están en la ciudad. Te das cuenta. En la ciudad todos están a la defensiva, no te dan propinas, o muy poco. En la playa es más tranquilo. Van a gastar, a divertirse, llevan tiempo. Es diferente.

Lo anterior muestra que la asociación entre contenidos de conciencia, trasciende la eventualidad del campo social y lo reconfigura adhiriéndose al significado que genera la agencia. Otro de los puntos importantes observados es que la noción de las estrategias de sustento se constituyó de varias implicaciones, tanto para el migrante a nivel personal, como para su familia y comunidad, a nivel social. Esto constata que la experiencia migratoria no solo involucra busqueda de bienestar económico. Así lo muestran varios de los entrevistados: 
[...] tú te vas, aquí tu familia vive en casitas pobres, van al día; llegas allá y encuentras trabajo, ganas bien y agarras una casita; tienes dinero, vives bien, lo que quieras, un carro; pero ¿tu familia? ¿Cuál es el sacrificio que haces? O sea, ya te olvidas de ellos: —allá que se jodan y tu disfrutando. Y pues no, siempre hay que ir para ayudar a los demás, a tu familia [...] Muchos se van y olvidan a su familia, regresan cuando su mamá ya se murió; [...] ya no los puede abrazar, decir: —mijo te quiero [...] Ya no tiene caso. Es lo más malo. Olvidarse de la familia (José, 2017).

Por su parte Ángeles (2017) menciona que "Estando allá valoras mucho a tu familia. A pesar de que estaba con mi hermano y mi hermana, extrañaba mucho a mis papás, su comida, todo extrañas, lo más mínimo". Esto refleja un punto nodal de la migración mexicana: el papel de la familia representa el pilar intencional de la trayectoria y, en torno a este establecen razones, motivaciones y objetivos. Esto significa que la amplitud del campo social trasciende fronteras a través de las agencias que realiza el migrante en la trayectoria de busqueda y, sobre todo, en la aplicación de las estrategias de sustento. Sin embargo, esto no implica ausencia de modificaciones personales. Abelardo (2017) por ejemplo, comenta que "[...] si yo no hubiera tenido aquí a mi mamá, no vuelvo jamás. En serio. Pero después dije: ¡no! yo me regreso, mi mamá anda sola por allá”. El fenómeno de la migración no representa el hecho de salir de casa en busca de alimento y retornar; en caso de que fuese así, tal hecho es en sí mismo una vivencia, en toda su aprehensión existencial; pero también, en toda su "comprehensión social".

De acuerdo con Long (2007, p. 117): "La noción de (livelihood) 'sustento' implica [...] más que ganarse la vida [...] Abarca las maneras y estilos de vida/vivir y, [...] optar entre distintos valores, asumir un estatus y un sentido de identidad vis a vis otras personas". Esto significa que la adaptación identitaria se visibiliza enfática en la etapa del retorno a través de livelihood, pues en este se vislumbra la manera en que el migrante trae a luz el contenido de conciencia, como significado holístico de la experiencia migratoria. Así lo relatan los actores de Tejupilco:

[...] La ventaja con la experiencia de ir a EUA, es que aprendes a relacionarte [...] la desventaja es que el tiempo que estuviste allá lo pierdes [...] tal vez tuviera una carrera, un trabajo estable [...] Pero si no me hubiera ido, menos hubiera estudiado, ¡con qué dinero! si por eso nos fuimos (Ángeles, 2017).

[...] aprendí la forma de trabajar de los americanos, sus ideas, por qué es que ellos progresan y su forma de progresar; algo que tal vez nosotros como mexicanos no nos adaptamos [...] aprendí que para progresar tienes que respetar tu trabajo, aunque sea tuyo tienes que llegar temprano y esforzarte más de lo normal, todo el tiempo; las 24 horas estar al pendiente de tu trabajo (Juan Carlos, 2017).

En el caso de Miguel (2017), después de más de veinte años de experiencia migratoria, comenta que su estatus en México es de "resignado por la deportación". Sin embargo, y con temple sereno, continúa: "Sólo tengo que pensar positivamente de que aquí también tengo que salir adelante". Menciona que a pesar del anhelo de estar con su familia (como la mayoria de los migrantes retornados con una trayectoria tan amplia): "No tengo la intención de regresar a EuA [...] mejor hay que echarle ganas". 
Por su parte, Guadalupe (2017) respondió a la pregunta "¿Valoras el sacrificio y malas experiencias que enfrentaste en EE. UU.?

Sí, para lo que soy ahora, para lo que es mi familia ahora, para lo que tenemos como familia, sí. Porque independientemente de los sacrificios, las experiencias que vivimos, malas algunas, te forjan como persona y te hacen ser lo que ahora eres y valorar lo que antes tenías y no aprovechaste.

La noción de Livelihood extiende su significado más allá de las estrategias económicas y se muestra como: "procesos de construcción de identidad inherentes a la persecución de los modos de sustento" (Long, 2007, p. 117). Ya que, como se ha mostrado anteriormente, implica: a) construcción de relaciones con otros cuyos mundos de vida y estatus pueden diferir notablemente; $b$ ) manejo de habilidades y relaciones; $c$ ) afirmación de importancia personal (autoestima) y $d$ ) identidad personal y de grupo (Long, 2007).

\section{Discusión}

El campo social es autorrealizable en cada una de las etapas migratorias a modo en que la conciencia del migrante asimila las experiencias y actúa a partir de estas. La vida cotidiana, base del campo social, se manifestó con cierta similitud en la mayoría de los casos analizados; las causas contextuales en el antes se observaron bajo la influencia migratoria de la localidad de origen (familiares, vecinos o conocidos) que facilitaron la actividad. Los objetivos planteados, como las fantasías, se observaron ofuscados al inicio de la etapa del durante en diferentes tipos de arenas, en el cruce para algunos, en la adaptación para la mayoría, así como el choque de una estructura social diferente y el conflicto cultural que representa. Sin embargo, dichos objetivos, fueron paulatinamente depurados, ampliados o proyectados en diferentes y nuevas perspectivas a través de múltiples agencias realizadas por los migrantes, develando nuevas decisiones, actitudes y modos de vida.

Las estrategias de sustento (livelihood) representaron el bagaje de arenas, dominios y agencias realizados de manera particular a través de las diferentes experiencias de los migrantes y, al igual que el campo social, en la etapa de retorno manifiestan una adaptación identitaria que si bien no devela un cambio radical, sí visibiliza una identidad en el lugar de origen que busca orientar los medios y estrategias de la vida cotidiana aprendida en el lugar de acogida. Hecho manifiesto en: el cambio de residencia del lugar de origen, estilo de vida, hábitos y vicios diferentes y, una actitud positiva a pesar de las dificultades políticas, económicas y sociales en la reinserción al lugar de origen.

Los resultados en este trabajo muestran que el análisis de la identidad en el marco migratorio adquiere relevancia al ser abordado desde una óptica más amplia, cuestionando de qué manera el cruce de fronteras trastoca la identidad personal, social o cultural del migrante. La estructura desarrollada desde la fenomenología con el construccionismo de Long muestra en primer lugar, que "las personas y sus ambientes [...] no responden con simpleza a los imperativos de marcos y normas culturales, o a los dictados de discursos dominantes" (Long, 2007, p. 27). En segundo lugar, la reducción al sujeto al poner entre paréntesis la contextualización del migrante 
y centrarnos a lo dado (factum) de las experiencias, permitió explicar "cómo se entrecruzan los significados, propósitos y poderes asociados con modos diferenciales de agencia humana para constituir los resultados de formas sociales emergentes" (Long, 2007, p. 27). Mostrando así una identidad de naturaleza maleable, que si bien está institucionalmente definida (Bagga-Gupta et al., 2017), introspectivamente opera en función de la intencionalidad de la experiencia migratoria adquirida. Estos resultados se suman a los esfuerzos heurísticos en la depuración de las dificultades que, de acuerdo con Ariza y Portes (2007, p. 38) "surgen cuando se intenta dilucidar el modo en que el cruce de fronteras altera los límites de la identidad".

Un estudio realizado por Arizpe (2015, p. 244) centra la pregunta: “¿Cómo se identifican a sí mismos los migrantes mexicanos?” La finalidad es definir bajo qué cultura se identifican: "prefieren a la cultura mexicana o la cultura estadounidense" (Arizpe, 2015, p. 249-250). El tema es abordado a través de virtudes de "lealtad cultural" que para Arizpe representan la cultura mexicana. Al comparar lo anterior con los resultados en este artículo, el tema de la identidad en la migración se muestra limitado por respuestas a preguntas estructuradas y definitorias. Esto se debe a que, de acuerdo con Ghiardo y Dávila (2008, p. 139): "El sujeto habla sólo a través de lo que el investigador supone como alternativas de respuesta posible, pero el sentido de su argumento queda mudo". La agencia permitió visibilizar la manera en que una experiencia, suceso o interacción social, puede sobreponerse mediante su significado, a nuevos contenidos experienciales y establecerse como directriz intencional de las decisiones del actor social; tal como Berger y Luckmann (2003) mencionan sobre el impacto causado al experimentar la transición de una realidad a otra. Por lo cual, se considera que el tema de la identidad en la migración requiere de un trabajo de análisis depurado sobre las experiencias, que logre describir la estructuración de dicha identidad. Esto permitirá que temas como intersubjetividad, interacción, intercomunicación y lenguaje, no sean considerados presupuestos al análisis de la identidad; ni que "el especialista en Ciencias Sociales ya tenga resuelto su problema fundamental antes de que comience la indagación científica” (Schutz, 1995, p. 75).

En la actualidad el tema del transnacionalismo es al parecer, la única vía teórica que devela interés al fenómeno de la identidad en el análisis migratorio (Ariza y Portes, 2007; Bretones y González-González, 2011; Moctezuma, 2013; Rodríguez, 2013). Este tipo de estudios, en lo que respecta a México, han conformado un sistema de aportaciones significativas al visibilizar, por ejemplo, los cambios estructurales de colectivos, gracias al impulso de la migración en la creación de redes sociales (Moctezuma, 2013); las relaciones transnacionales y el contraste de estilos de vida que se desarrollan en las comunidades fronterizas de México (Rodríguez, 2013), entre otros. Sin embargo, el enfoque de la epojé considera implicaciones al análisis de las causas empíricas que hayan provocado de manera particular el flujo migratorio. Lo cual permite ubicar una investigación cualitativa con base en datos de las experiencias de los migrantes (Ghiardo y Dávila, 2008; Husserl, 2011; Zarur, 2016). Esto es de suma importancia ya que, de acuerdo con Long:

Los actores sociales no deben figurar como simples categorías sociales incorpóreas (basadas en la clase o algún otro criterio clasificatorio), o destinatarios pasivos de la intervención, sino como participantes activos que reciben e interpretan información y diseñan estrategias en sus relaciones con los diversos actores locales, así como con las instituciones externas y su personal (Long, 2007, p. 43). 
Nuestros resultados advierten que el cambio de identidad puede configurarse en la medida en que el migrante adquiere experiencia de las relaciones sociales en las que se desenvuelve como tal (dificultades en la adaptación, aprendizaje del idioma, creación de nuevos proyectos, entre otros). Aún partiendo del hecho tradicional que enmarca la causa de la migración como factor laboral (en la mayoría de los casos), no significa necesariamente que el panorama acumulativo de experiencias, conocimiento y aprendizaje sea exclusivamente de la misma naturaleza (Zarur, 2016). Según Nicolás:

Migrar a otro país en busca de un mejor empleo y mejores condiciones de subsistencia es una práctica que modifica el curso de vida personal, familiar y comunitaria. La experiencia migratoria reconfigura sentidos y significados en los individuos, sus familias y los grupos a los que pertenecen a lo largo de la trayectoria migratoria (Nicolás, 2016, p. 208).

El fenómeno migratorio observado bajo el enfoque del mundo de la vida que propone la fenomenología (Berger y Luckmann, 2003; Husserl, 2008; 2011; 2013; Schutz, 1995) se va estructurando en un campo irregular a través del dinamismo que ejercen los actores, como lo propone Long (2007). Esto significa que la vida del migrante no se limita exclusivamente a experiencias laborales, como se observó en la etapa del retorno con el concepto de livelihood. Subyacentes a estas, adquiere experiencias más allá de las habilidades y aplicaciones prácticas aprendidas. Los resultados muestran la manera en que estas experiencias generan paralelamente un bagaje cualitativo que identifica gradualmente al migrante con el contexto social en que se desarrolla; y contribuyen a que encuentren sentido y asentamiento, permitiéndoles definirse como alguien en particular en un contexto cultural distinto al de origen a través de conflictos axiológicos y culturales (Schwartz, 2005; Schwartz et al., 2006).

Situándonos en la frontera México-Estados Unidos, Kearney (2006) menciona que el ejercicio fronterizo es en última instancia una dinámica económica, más bien el papel es dictaminar la identidad cultural de las personas que son circunscritas y excluidas en el acto del cruce. Sin embargo, a través del concepto de dominio, los resultados muestran que cada experiencia es individual, aunque suceda en el mismo contexto. Asimismo, una declaración argumentativa puede presentarse de manera individual, pero puede también encontrar fundamento en la colectividad simbólica que representa la experiencia migratoria en mayoría: "quien no sabe que ir al norte es a chingarse [sic] y aguantar todo lo que le pase, mejor que ni vaya" (José, 2017). La condicionante global identitaria que muestra Bagga-Gupta et al. (2017), en el migrante mexicano está inconscientemente sobreentendida; así se muestra en los resultados aquí obtenidos. Pero también se observó que es el riesgo que aceptan y a través del cual proyectan sus esperanzas en la construcción de una identidad dinámica y maleable que se configura en la búsqueda de una vida mejor, tanto para el migrante como para la familia.

La perspectiva de la construcción social bajo el enfoque de la epojé hace pertinente cuestionar el interés heurístico actual por la identidad del sujeto migrante como actor social; si en realidad dicho interés se centra en el migrante o en observar desde una óptica global, cómo el velero de la migración mexicana es también, heurísticamente manipulable por el viento político y económico del país receptor. Existe la necesidad de cuestionar cuál es el efecto en la identidad del migrante mexicano bajo la imposición del Norte global (Bagga-Gupta et al., 2017) que acepta y adopta (Schwartz, 2005; 
Schwartz et al., 2006) y, que repercute en la readaptación al retornar al lugar de origen (Rivera, 2016). O bien, de qué manera esta adaptación constituye la construcción de una identidad gestada en la postura que denigra y define en el discurso de las estructuras globales.

Lo anterior permite dos observaciones pertinentes: 1) la influencia y predominio de poderes comerciales y valores culturales constituyen un condicionamiento sobre realidades y fenómenos sociales; 2) el condicionamiento de dicha estructura es de tal magnitud que, la idea "Estado nación" se ha naturalizado en nuestra imaginación global colectiva (Bagga-Gupta et al., 2017) al grado que la observación heurística de realidades y fenómenos sociales, también se muestra enraizada y condicionada por tales estructuras. Esto es claro al admitir que "en un mundo globalizado, basado en modelos económicos y patrones de acumulación globales, no cabe duda de que la migración ha de ser pensada y analizada en términos de su globalización" (Canales, 2013, p. 10). El resultado de ello es la conceptualización de las experiencias en temas de características propias a un sector social definido, con objeto de mostrar un contexto generalizado de los fenómenos que se estudian sociológicamente (Long, 2007; Zarur, 2016). Esto significa que se sigue generalizando a las vivencias como categorizaciones sociales, cuando, la individualidad "es (esencialmente) con" la vivencia y no un accidente de esta.

Ahora bien, qué sucede en los casos en que el retorno migratorio se devela como proceso de readaptación donde el migrante "podría ser un extranjero en su propia tierra" y vivenciar, en cierto modo, lo que experimentó en el extranjero (Rivera, 2016). O bien, cuando "la reinserción funciona más bien como una expectativa [...] de ser incluido, aceptado o bienvenido socialmente, situación que no necesariamente se cumple" (Rivera, 2016, p. 118). Parece clara la necesidad de apertura a la identidad del migrante como un problema emergente. Sería adecuado entonces, cuestionar ¿cuáles son las circunstancias sociales en las que se desenvuelve el migrante para determinar un cambio en su identidad? Ya que, en este sentido el retorno es representado como factor de cambio en el lugar de origen. Los resultados obtenidos en este trabajo, a través de las categorías analíticas, son congruentes al estudio realizado por Rivera (2016) donde, se observa que: "las descripciones detalladas contenidas en las narrativas permiten identificar cómo las experiencias de los inmigrantes son movilizadas y cómo los arreglos para desplazarse a través de diversos lugares se relacionan con variados procesos vitales e históricos" (Rivera, 2016, p. 140). O también, cuando enuncia que "el concepto de inserción exhibe limitaciones heurísticas para comprender la experiencia de regresar a México, después de vivir en Estados Unidos" (Rivera, 2016, p. 118). Asimismo, en el análisis de los componentes culturales e identitarios que devela Nicolás en la relación migrante-terruño donde, se observa en qué medida la experiencia migratoria influye en dicha relación, ya sea conectando o separando a las personas; y "entender el modo en que lo estructural actúa en lo concreto, la vivencia de las personas" (Nicolás, 2016, p. 219).

\section{Conclusiones}

Los resultados obtenidos de este análisis se adecuan a la situación actual que experimenta México con EE. UU., donde la posición del migrante mexicano es 
definida por el influjo del discurso macrosocial que lo restringe, no acepta y repudia pero que, paradójicamente, necesita para hacer funcionar la economía. En este estudio se encontraron ideas sólidas que permiten develar que el discurso también es una construcción social que deriva de las experiencias y, que es gestado en reflexiones interpretativas de la vida social que constituyen representaciones significativas; racionalizaciones estructurales organizadas expresadas como unidades sistémicas a través del lenguaje.

Por otro lado, este trabajo permitió observar la necesidad de la apreciación fenomenológica en las experiencias de los migrantes y delinear vías que comprendan aquello que los estudios sociodemográficos por su limitación y perfil de análisis no pueden visibilizar. Centrar el objeto de estudio desde esta perspectiva dejó contemplar el retorno migratorio no como fin del camino, sino como introspección que da cuenta amplia de la particularidad de la migración a través de las vivencias. Esto permite reconocer que los migrantes retornados, como colectivo, no solo representan un actor social externo, sino una identidad constituida en un contexto diferente.

Las limitaciones en esta investigación representan el giro cualitativo que sugiere indagar el fenómeno migratorio desde una perspectiva separada de la observación con base a la estadística y un enfoque cuantitativo. El enfoque fenomenológico tiene de base la óptica filosófica de la epojé husserliana la cual, fuera de este campo, representa limitaciones no únicamente teóricas y metodológicas, sino epistemológicas. Argumentar sobre un fenómeno social dejando de lado los datos empíricos que lo sustentan, parece ser "per se" una contradicción. Sin embargo, es en esta paradoja en la que se sustentó la propuesta teórica expuesta. En este sentido, el esfuerzo heurístico de abordar esta limitante representó un reto personal y profesional que puede proyectarse en depuraciones a futuras investigaciones.

Los resultados dan a conocer que la naturaleza dinámica de la identidad no depende de definiciones macrosociales, sino, en la actividad que realiza el sujeto como capacidad de ser actor social. En este sentido, la generación inductiva de conocimiento en la Teoría Fundamentada permitió develar que la capacidad de personalización debe ser comprendida en la creatividad y preocupación de sí mismo, como identidad compuesta de significado, donde la subjetividad sea la internalización operativa del sujeto que se reconoce proactivo en la interacción con su contexto social. El retorno al sujeto realizado a través de la epojé devela que el cambio de identidad en la experiencia migratoria está en el contenido existencial de ésta y no, en la definición de las estructuras globales.

\section{Agradecimientos}

Los autores agradecemos al Consejo Nacional de Ciencia y Tecnología por la beca otorgada a uno de los autores para la realización de sus estudios de Maestría en Ciencias Agropecuarias y Recursos Naturales. Agradecemos los comentarios realizados por la Dra. Itzel Hernández Lara y por los árbitros que revisaron este artículo. 


\section{Referencias}

Anguiano, M. E. y Cardoso, M. (2012). Redes sociales en la migración internacional mexiquense. En J. G. González y J. Montoya (Comps.), Migración mexiquense a Estados Unidos: Un análisis interdisciplinario (pp. 213-229). Toluca, México: Universidad Autónoma del Estado de México, Centro de Investigación y Estudios Avanzados de la Población.

Ariza, M. (2016). Emociones, afectos y Sociología. Diálogos desde la investigación social y la interdisciplina. México: Universidad Nacional Autónoma de México, Instituto de Investigaciones Sociales.

Ariza, M. y Portes, A. (2007). El país transnacional: Migración mexicana y cambio social a través de la frontera. México: Universidad Nacional Autónoma de México.

Arizpe, L. (2015). El mundo se está volviendo más peligroso. En L. Arizpe, Vivir para crear Historia. Antología de estudios sobre desarrollo, migración, género e identidades (pp. 241-255). México: Universidad Nacional Autónoma de México, Porrúa.

Bagga-Gupta, S., Hansen, A. y Feilberg, J. (2017). Conceptual Framings of Identity in a Multifaceted World. En S. Bagga-Gupta, A. Hansen y J. Feilberg (Eds.), Identity Revisited and Reimagined. Empirical and Theoretical Contributions on Embodied Communication Across Time and Space (pp. 1-23). Cham, Suiza: Springer.

Benwell, B. y Stokoe, E. (2006). Discourse and identity. Edinburgo, Reino Unido: Edinburgh University Press.

Berger, P. L. y Luckmann, T. (2003). La construcción social de la realidad. Buenos Aires, Argentina: Amorrortu editores.

Bretones, F. y González-González, J. (2011). Identidad y migración: La formación de nuevas identidades transculturales. En H. M. Cappello y M. Recio (Eds.), La identidad nacional. Sus fuentes plurales de construcción (pp. 137-164). México: Plaza y Valdés Editores.

Bucholtz, M. y Hall, K. (2005). Identity and Interaction: A Sociocultural Linguistic Approach. Discourse Studies, 7(4-5), 585-614. Recuperado de https://escholarship.org/uc/item/5tk670n8

Canales, A. I. (2013). La migración en la reproducción de la sociedad global. Migración y Desarrollo, 11(21), 9-41. Recuperado de www.redalyc.org/articulo. oa?id=66029968002

Castles, S. (2014). Las fuerzas tras la migración global. Revista Mexicana de Ciencias Políticas y Sociales, LIX(220), 235-259. Recuperado de http://www.redalyc.org/ articulo.oa?id $=42131173008$

Coté, J. (2006). Identity Studies: How Close are we to Developing a Social Science of Identity? An Appraisal of the Field. Identity: An International Journal of Theory and Research, 6(1), 3-25. doi: 10.1207/s1532706xid0601_2

Dubar, C. (2002). La crisis de las identidades: La interpretación de una mutación. Barcelona, España: Bellaterra.

Dubet, F. y Zapata, F. (1989). De la sociología de la identidad a la sociología del sujeto. Estudios Sociológicos, VII(21), 519-545. Recuperado de https://estudiossociologicos.colmex.mx/index.php/es/article/view/1088/1088

Dreher, J. (2012). Fenomenología: Alfred Schutz y Thomas Luckmann. En E. de la Garza y G. Leyva (Eds.), Tratado de metodología de las Ciencias Sociales: Perspectivas 
actuales (pp. 97-139). México, Distrito Federal: Fondo de Cultura Económica, Universidad Autónoma Metropolitana.

Fox, J. y Rivera-Salgado, G. (2004). Indígenas mexicanos migrantes en los Estados Unidos. México, Distrito Federal: Universidad de California, Santa Cruz; Universidad Autónoma de Zacatecas.

Gandini, L., Lozano-Ascencio, F. y Gaspar, S. (2015). El retorno en el nuevo escenario de la migración entre México y Estados Unidos. Recuperado de https://www.gob.mx/ cms/uploads/attachment/file/39174/ElRetornoEnelNuevoEscenariodeMigracion.pdf

Ghiardo, F. y Dávila, O. (2008). Trayectorias sociales juveniles. Ambivalencias y discursos sobre el trabajo. Santiago de Chile: Instituto Nacional de la Juventud, Centro de Estudios Sociales CIDPA.

Giménez, G. (1993). Apuntes para una teoría de la identidad nacional. Sociológica, 8(21), 13-29. Recuperado de https://dialnet.unirioja.es/servlet/articulo?codigo $=4397359$

Giménez, G. (1996). La identidad social o el retorno del sujeto en sociología. En L. I. Méndez, Identidad (pp. 183-208). México: Universidad Nacional Autónoma de México.

Giménez, G. (1997). Materiales para una teoría de las identidades sociales. Frontera Norte, 9(18), 9-28.

Giménez, G. (2000). Identidades en globalización. Espiral, ИІІ(19), 27-48.

Glaser, B. G. y Strauss, A. L. (1967). The Discovery of Grounded Theory. Strategies for Qualitative Research. Nueva York, Estados Unidos: AldineTransaction.

González, J. G. (2012). Antecedentes de la emigración internacional del Estado de México. En J. G. González y J. Montoya (Comps.), Migración mexiquense a Estados Unidos: Un análisis interdisciplinario (pp. 111-130). Toluca, México: Universidad Autónoma del Estado de México, Centro de Investigación y Estudios Avanzados de la Población.

González, J. G. y López, R. (2012). Magnitud y características de la emigración de los mexiquenses a Estados Unidos. En J. G. González y J. Montoya (Comps.), Migración mexiquense a Estados Unidos: Un análisis interdisciplinario (pp. 159-177). Toluca, México: Universidad Autónoma del Estado de México, Centro de Investigación y Estudios Avanzados de la Población.

González, J. G., Montoya, J. y López, R. (2012). Encuesta sobre migración de mexiquenses a Estados Unidos EMMEU 2009. Tabulados básicos. Toluca, México: Universidad Autónoma del Estado de México, Centro de Investigación y Estudios Avanzados de la Población.

Heath, H. y Cowley, S. (2004). Developing a Grounded Theory Approach: A Comparison of Glaser and Strauss. International Journal of Nursing Studies, 41, 141150. Recuperado de https://pdfs.semanticscholar.org/b5b1/381daf169fd926e252e510ae9171f9264366.pdf

Heidegger, M. (1971). El ser y el tiempo. México, Distrito Federal: Fondo de Cultura Económica.

Heidegger, M. (1990). Identidad y diferencia. Barcelona, España: Anthropos.

Heidegger, M. (2013). Seminarios de Zollikon (1959-1969). México, Distrito Federal: Herder. 
Husserl, E. (1997). Ideas relativas a una fenomenología pura y una filosofía fenomenológica II. México: Instituto de Investigaciones Filosóficas, Universidad Nacional Autónoma de México.

Husserl, E. (2008). La crisis de las ciencias europeas y la fenomenología trascendental. Buenos Aires, Argentina: Prometeo Libros.

Husserl, E. (2011). La idea de la fenomenología. Barcelona, España: Herder.

Husserl, E. (2013). Ideas relativas a una fenomenología pura y una filosofía fenomenológica. Libro primero: Introducción general a la fenomenología pura. México: Instituto de Investigaciones Filosóficas, Universidad Nacional Autónoma de México, Fondo de Cultura Económica.

Jardón, A. E. y Corona, R. (2012). Prácticas transnacionales de los migrantes laborales de origen mexiquense. En J. B. González y J. Montoya (Comps.), Migración mexiquense a Estados Unidos: un análisis interdisciplinario (pp. 131-157). Toluca, México: Universidad Autónoma del Estado de México, Centro de Investigación y Estudios Avanzados de la Población.

Kearney, M. (2006). El poder clasificador y filtrador de las fronteras. En F. Besserer y M. Kearney, San Juan Mixtepec una comunidad ante el poder clasificador y filtrador de las fronteras (pp. 31-71). México: Casa Juan Pablo, Fundación Rockefeller, Universidad de California Riverside,Universidad Autónoma Metropolitana-Iztapalapa.

Long, N. (2007). Sociología del desarrollo: Una perspectiva centrada en el actor. San Luis Potosí, México: El Colegio de San Luis, ciesas.

Moctezuma, M. (2013). Retorno de migrantes a México. Su reformulación conceptual. Papeles de Población, 19(77), 149-175. Recuperado de http://www.scielo. org.mx/pdf/pp/v19n77/v19n77a9.pdf

Nicolás, P. (2016). De regreso al terruño: Reinserción sociocultural de migrantes indígenas mazahuas retornados de Estados Unidos. En J. Olvera y N. Baca (Coords.), Continuidades y cambios en las migraciones de México a Estados Unidos. Tendencias en la circulación, experiencias y resignificaciones de la migración y el retorno en el Estado de México (pp. 203-228). Toluca, México: Universidad Autónoma del Estado de México, Universidad de Texas San Antonio.

Patton, M. Q. (2002). Qualitative Research and Evaluation Methods. California, Estados Unidos: Sage Publications.

Rivera, L. (2016). ¿Volver a casa? Desafíos y rutas divergentes de migrantes de retorno. En J. Olvera y L. Baca (Coords.), Continuidades y cambios en las migraciones de México a Estados Unidos (pp. 115-144). Toluca, México: Universidad Autónoma del Estado de México, Universidad de Texas San Antonio.

Rodríguez, R. (2013). Cultura e identidad en la región fronteriza México-Estados Unidos. México, Distrito Federal: Eón.

Román, P. (2012). La encuesta sobre migración de mexiquenses a Estados Unidos EMMEU 2009. En J. G. González y J. Montoya (Comps.), Migración mexiquense a Estados Unidos: Un análisis interdisciplinario (pp. 17-33). Toluca, México: Universidad Autónoma del Estado de México, Centro de Investigación y Estudios Avanzados de la Población.

Salas, R. (2017). Los migrantes retornados a la Región Tejupilco, Estado de México. CIENCIA ergo-sum, 24(2), 117-125. Recuperado de https://dialnet.unirioja.es/servlet/articulo?codigo $=6046442$ 
Salas, R. y Alcántara, M. (2015). La migración internacional de retorno en el suroeste del Estado de México. En N. Baca y R. Salas (Coords.), Migración internacional, territorios y sujetos migrantes del Estado de México (pp. 75-93). México, Distrito Federal: Ediciones Eón.

Salas, R. y Baca, N. (2016). Configuraciones familiares y género en el Sur mexiquense. Revista CIMEXUS, XI(1), 31-44.

Sánchez, F. (2016). Lo emocional en el vaivén de los migrantes no autorizados del noroeste del Estado de México a Estados Unidos. En J. Olvera y N. Baca (Coords.), Continuidades y cambios en las migraciones de México a Estados Unidos. Tendencias en la circulación, experiencias y resignificaciones de la migración y el retorno en el Estado de México (pp. 397-419). Toluca, México: Universidad Autónoma del Estado de México, Universidad de Texas San Antonio.

Sánchez Ortiz de Urbina, R. (2015). Campo intencional y campo kinestésico como campo dual. Eikasia, Revista de Filosofía, (64), 9-22. Recuperado de http://www. revistadefilosofia.org/64-01.pdf

Secretaría de Desarrollo Social (Sedesol). (2015). Catálogo de localidades. Recuperado de http://www.microrregiones.gob.mx/catloc/LocdeMun.aspx?tipo=clave\&campo $=$ loc\&ent $=15 \&$ mun $=082$

Searle, J. (1997). La construcción de la realidad social. Barcelona, España: Paidós.

Schutz, A. (1995). El problema de la realidad social. Escritos, I. Buenos Aires, Argentina: Amorrortu.

Schutz, A. y Luckmann, T. (2003). Las estructuras del mundo de la vida. Buenos Aires, Argentina: Amorrortu.

Schütz, A. (2004). Der Sinnhafte Aufbau der Sozialen Welt. Werkausgabe, Bd. II. M. Endreß y J. Renn (Eds.). Konstanz, Alemania: Uvk.

Schwartz, S. J. (2005). A New Identity for Identity Research: Recommendations for Expanding and Refocusing the Identity Literature. Journal of Adolescent Research, 20(3), 293-308. doi: 10.1177/0743558405274890

Schwartz, S. J., Montgomery, M. J. y Briones, E. (2006). The Role of Identit y in Acculturation Among Immigrant People: Theoretical Propositions, Empirical Questions, and Applied Recommendations. Human Development, (49), 1-30. Recuperado de https://pdfs.semanticscholar.org/dc3f/6960f12bd1db3f4b2e3d1f33bcaeba180571.pdf

Strauss, A. y Corbin, J. (2002). Bases de la investigación cualitativa. Técnicas y procedimientos para desarrollar la Teoría Fundamentada. Medellín, Colombia: Universidad de Antioquia.

Weber, M. (2014). Economía y sociedad. México: Fondo de Cultura Económica.

Wetherell, M. (2010). The field of identity studies. En M. Wetherell y C. T. Mohanty (Eds.), The Sage Handbook of Identities (pp. 3-26). Londres, Reino Unido: SAGE.

Wetherell, M. y Mohanty, C. T. (2010). The Sage Handbook of Identities. Londres, Reino Unido: SAGE.

Zarur, A. (2016). Lo que no se fue en el veliz azul. Relato de vida de Rafael un migrante tonatiquense. En J. Olvera y N. Baca (Coords.), Continuidades y cambios en las migraciones de México a Estados Unidos. Tendencias en la circulación, experiencias y resignificaciones de la migración y el retorno en el Estado de México (pp. 377-395). Toluca, México: Universidad Autónoma del Estado de México, Universidad de Texas San Antonio. 


\section{Entrevistas}

Abelardo. (2017). Migración de retorno en Tejupilco / Entrevistador: Felipe de Jesús Rodríguez Díaz. Estrategias de sustento entre los jóvenes del medio rural en el sur del Estado de México, UaEmex-Instituto de Ciencias Agropecuarias y Rurales, Tejupilco, Estado de México.

Ángeles. (2017). Migración de retorno en Tejupilco / Entrevistador: Felipe de Jesús Rodríguez Díaz. Estrategias de sustento entre los jóvenes del medio rural en el sur del Estado de México, Uaemex-Instituto de Ciencias Agropecuarias y Rurales, Tejupilco, Estado de México.

Ariel. (2017). Migración de retorno en Tejupilco / Entrevistador: Felipe de Jesús Rodríguez Díaz. Estrategias de sustento entre los jóvenes del medio rural en el sur del Estado de México, uafmex-Instituto de Ciencias Agropecuarias y Rurales, Tejupilco, Estado de México.

Guadalupe. (2017). Migración de retorno en Tejupilco / Entrevistador: Felipe de Jesús Rodríguez Díaz. Estrategias de sustento entre los jóvenes del medio rural en el sur del Estado de México, uaEmex-Instituto de Ciencias Agropecuarias y Rurales, Tejupilco, Estado de México.

Humberto. (2017). Migración de retorno en Tejupilco / Entrevistador: Felipe de Jesús Rodríguez Díaz. Estrategias de sustento entre los jóvenes del medio rural en el sur del Estado de México, uAEmex-Instituto de Ciencias Agropecuarias y Rurales, Tejupilco, Estado de México.

José. (2017). Migración de retorno en Tejupilco / Entrevistador: Felipe de Jesús Rodríguez Díaz. Estrategias de sustento entre los jóvenes del medio rural en el sur del Estado de México, uafmex-Instituto de Ciencias Agropecuarias y Rurales, Tejupilco, Estado de México.

Juan Carlos. (2017). Migración de retorno en Tejupilco / Entrevistador: Felipe de Jesús Rodríguez Díaz. Estrategias de sustento entre los jóvenes del medio rural en el sur del Estado de México, uaEmex-Instituto de Ciencias Agropecuarias y Rurales, Tejupilco, Estado de México.

Lourdes. (2017). Migración de retorno en Tejupilco / Entrevistador: Felipe de Jesús Rodríguez Díaz. Estrategias de sustento entre los jóvenes del medio rural en el sur del Estado de México, Uaemex-Instituto de Ciencias Agropecuarias y Rurales, Tejupilco, Estado de México.

Miguel. (2017). Migración de retorno en Tejupilco / Entrevistador: Felipe de Jesús Rodríguez Díaz. Estrategias de sustento entre los jóvenes del medio rural en el sur del Estado de México, UaEmex-Instituto de Ciencias Agropecuarias y Rurales, Tejupilco, Estado de México.

Sergio. (2017). Migración de retorno en Tejupilco / Entrevistador: Felipe de Jesús Rodríguez Díaz. Estrategias de sustento entre los jóvenes del medio rural en el sur del Estado de México, UaEmex-Instituto de Ciencias Agropecuarias y Rurales, Tejupilco, Estado de México. 
Felipe de Jesús Rodríguez

Mexicano. Licenciado en Filosofía por el Instituto Salesiano de Estudios Superiores. Actualmente realiza su Maestría en Ciencias Agropecuarias y Recursos Naturales en el Instituto de Ciencias Agropecuarias y Rurales de la Universidad Autónoma del Estado de México.

\section{Sergio Moctezuma Pérez}

Mexicano. Doctor en Antropología Social por la Universidad Iberoamericana, Ciudad de México. Actualmente es profesor-investigador en el Instituto de Ciencias Agropecuarias y Rurales de la Universidad Autónoma del Estado de México. Es miembro del Sistema Nacional de Investigadores Nivel I. Línea de investigación: los cambios y continuidades en las sociedades rurales de México. Entre sus publicaciones recientes: Moctezuma, S. (2017). Una aproximación a las sociedades rurales de México desde el concepto de aprendizaje vicario. LiminaR. Estudios Sociales y Humanísticos, 15(2), 169-178.

Humberto Thomé-Ortiz

Mexicano. Doctor en Ciencias Agrarias por la Universidad Autónoma Chapingo. Actualmente es Profesor-Investigador definitivo en el Instituto de Ciencias Agropecuarias y Rurales de la Universidad Autónoma del Estado de México, donde también se desempeña como coordinador de la Maestría en Agroindustria Rural, Desarrollo Territorial y Turismo Agroalimentario. Líneas de investigación: transiciones rurales, sistemas agroalimentarios localizados y turismo agroalimentario. Entre sus publicaciones más recientes: Thomé-Ortiz, H. (2018). Heritage cuisine and identity: Free time and its relation to the social reproduction of local food. Journal of Heritage Tourism, 13(2), 104-114. 